\title{
Genotypic testing in clinically defined HHT: would Osler approve or turn in his grave?
}

\author{
${ }^{1} \mathrm{R}$ Kettritz, ${ }^{2} \mathrm{C}$ Hinrichs, ${ }^{3} \mathrm{CE}$ Althoff, ${ }^{4} \mathrm{FC}$ Luft \\ ${ }^{1}$ Attending Nephrologist, Nephrology Department and Experimental and Clinical Research Center, Faculty of the Charite and Max-Delbrück \\ Center for Molecular Medicine; ${ }^{2}$ Resident in Nephrology; ${ }^{3}$ Consultant Radiologist, Radiology Section, Charite Campus Virchow Klinikum, \\ ${ }^{4}$ Director of Experimental and Clinical Research Center, Charite and Max-Delbrück Center for Molecular Medicine, Berlin, Germany
}

\begin{abstract}
Modern diagnostic possibilities pose a number of challenges. When is a precise genetic diagnosis justifiable in today's climate of cost-cutting? We would like to pose that question to Sir William Osler. Sir William was a keen observer, a master 'translator' of science into clinical medicine. Would he have required or supported genetic testing? We treated a patient whose case reminded us of Sir William's belief that clinical exactness was the ultimate aim, regardless of cost.
\end{abstract}

KEYWORDS Hemorrhagic hereditary telangiectasia, Osler, genetic testing, clinical medicine, medical education

DECLARATION OF INTERESTS No conflicts of interest declared.

\author{
Correspondence to R Kettritz \\ Experimental and Clinical \\ Research Center, \\ Lindenberger Weg 80, \\ I3 I25 Berlin, Germany
}

tel. +4930450540002

e-mail kettritz@charite.de

\section{CASE REPORT}

A 7l-year-old woman was admitted to the hospital due to progressive dyspnoea over the previous two weeks. Five years ago one of her breasts had been removed because of cancer and the area was irradiated. She had undergone aortic valve replacement four years earlier because of calcific aortic stenosis. A post-operative echocardiographic assessment suggested a residual pressure gradient of $40 \mathrm{~mm} \mathrm{Hg}$ across the valve. On admission, a transthoracic echocardiogram showed a pressure gradient of approximately $100 \mathrm{~mm} \mathrm{Hg}$ with a valve area estimated as $\langle 1 \mathrm{~cm}$.' $A$ chest roentgenogram indicated a diagnosis of congestive heart failure. Laboratory values yielded haemoglobin $(\mathrm{Hb})$ levels of 9.7 grams per decilitre $(\mathrm{g} / \mathrm{dL})$, a hematocrit level of $3 \mathrm{I}$ volume per cent, a mean cell volume of 93 femtoliters (fL), mean corpuscular haemoglobin levels of 29.1 picogram (pg), a mean corpuscular haemoglobin concentration of $31.7 \mathrm{~g} /$ $\mathrm{dL}$, with normal leukocyte and platelet counts. The haptoglobin level was $<20 \mathrm{mg} / \mathrm{dl}$, although no paravalvular leak was observed. The ferritin concentration was 56 nanograms per millilitre $(\mathrm{ng} / \mathrm{mL})$, while the transferrin saturation was seven per cent. The serum iron concentration was 4.2 micromoles per litre of blood $(\mu \mathrm{mol} / \mathrm{L})$.The creatinine concentration was 0.72 milligrams per decilitre $(\mathrm{mg} / \mathrm{dL})$. The patient had anaemia and iron deficiency appeared to be present. An upper and lower endoscopy were performed and showed no bleeding sites or suspicious lesions. We found no basis for haemolysis.

On careful re-examination of the patient, we observed a single, raised, reddish lesion on the patient's left internal buccal area as well as on one of her fingers. A review of her family history indicated that the patient's father had similar skin lesions that were occasionally prone to rupture. Our patient had two daughters and both had recurrent nosebleeds. A more careful abdominal examination disclosed a systolic murmur that was audible in the upper abdomen. We reviewed the Curacao criteria for hemorrhagic hereditary telangiectasia (HHT, also known as Osler-Weber-Rendu syndrome): ${ }^{2}$ epistaxis, telangiectasia, visceral malformations and a positive family history of the disease. To clarify the abdominal bruit, we performed a computed tomography (CT) angiogram of her viscera (Figures IA and IB).'

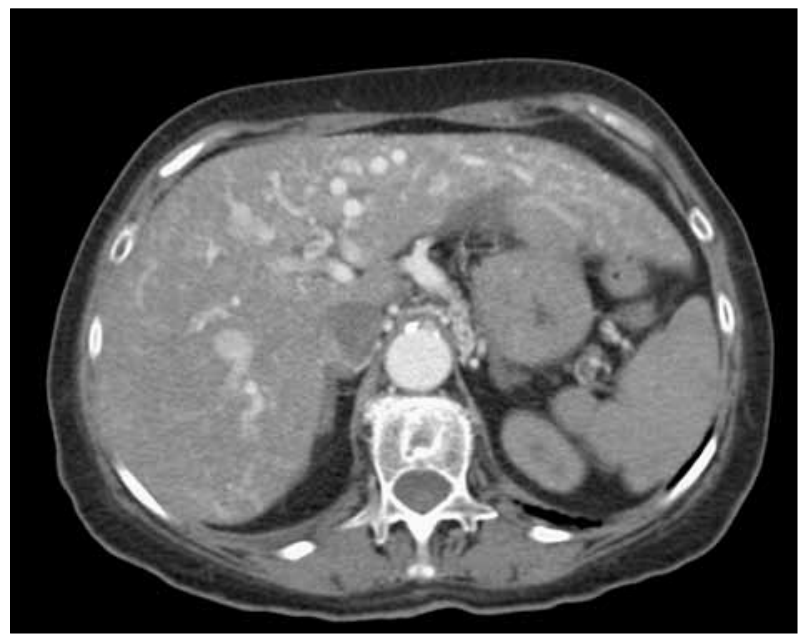

FIGURE IA Computed tomography (CT) scan with contrast showing numerous arteriovenous malformations in the liver. 


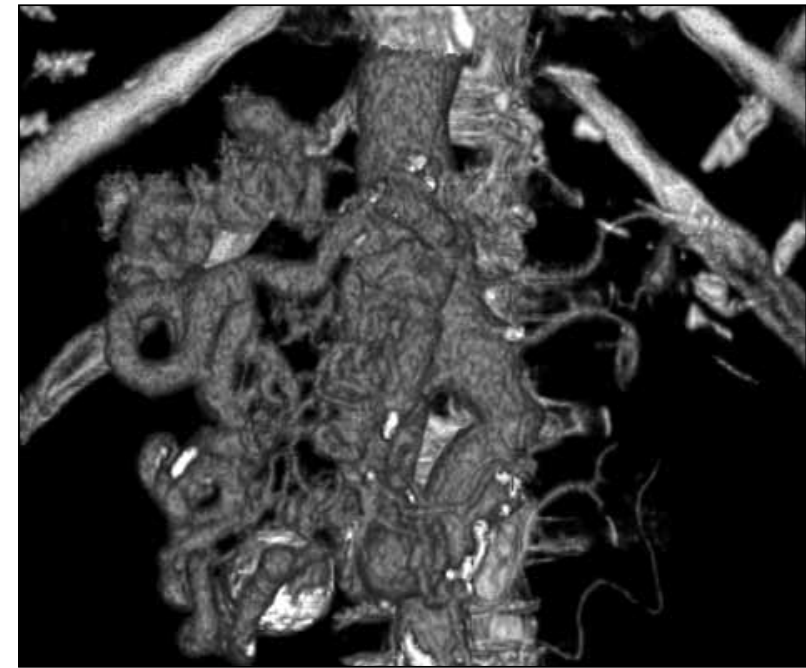

FIGURE IB A computerised construction of the image of the liver.

\section{DISCUSSION}

Based on the clinical evidence, we believed that our patient had HHT and that the next stage was to establish a genetic diagnosis. However, Shovlin et al. ${ }^{3}$ state that 'for patients with definite clinical HHT, molecular testing is not required to establish the diagnosis'. They suggested that a clinically obvious case does not require genetic analysis, except when a mutation is suspected in the SMAD4 gene; how this rare possibility is to be confirmed clinically is less clear. Shovlin also discussed the different types of screening: ${ }^{3}$ when there is a benefit and no harm, when there is a benefit but possible harm, when there is no benefit to screening, but no harm, when there is no benefit and possible harm. In our case we established that screening would cause no harm but would have no benefits for the patient; the only benefit might be for subsequent grandchildren.We believed that our students on the other hand would benefit by making the association between this patient's test results and the precise pathophysiology of her condition. However, directing them to a textbook or to the Internet may have achieved the same result. On making our final decision to undertake expensive genetic testing, we relied on Sir William Osler's belief that: 'To study the phenomenon of disease without books is to sail an uncharted sea, while to study books without patients is not to go to sea at all. ${ }^{4}$ We discussed the screening options with our patient; the gene test would have little consequence for her and her children, but there might be some benefits for her grandchildren, although this could not be guaranteed. The patient agreed to genetic testing. We could have taken her blood for DNA storage on behalf of her future family members and allowed them to decide at a later date what should be done. Genetic diagnostic tests have changed dramatically in the last 20 years and could again in the next. Invasion of privacy issues, insurance consequences and other concerns are reiterated elsewhere by Becker et al. ${ }^{5}$ Physicians and students caring for this patient examined her endoglin levels, the activin receptor-like kinase (ALKI) levels and her SMAD4 genes. They investigated the transforming growth factor beta (TGF- $\beta$ ) signalling pathway in order to establish how this mutation worked in their patient, a woman with multiple medical problems, undiagnosed for so long. We elected to sequence the genes in question and identified a previously known ALKI (ACVRLI) mutation. Genetic testing provided the surgeons, who were faced with replacing the patient's aortic valve, with detailed information about the challenge they faced. The patient was satisfied with a diagnosis of a rare genetic disease, the cause of which was now known. The physicians and students established a genetic disease down to the last base pair, showing the value of taking a detailed history and performing a physical examination, as well as looking to molecular biology for the answers. There were however some negative consequences to the decision to perform genetic testing: the body responsible for the financial implications refused to pay the $€ 4,000$ sequencing bill even though a diseaserelevant mutation was found. Our university public hospital was forced to pay the cost and we received official reprimands for our decision.

\section{LITERATURE REVIEW}

The terms 'gene tests and diagnosis-related groups' resulted in 198 entries. In the most recent paper, Antonanzas et al studied the economic relevance of genetic testing in the European Union. ${ }^{6}$ They conducted a systematic literature review and found approximately 3,500 papers relevant to their topic. The most studied diseases were cystic fibrosis, breast and ovarian cancer, hereditary hemochromatosis, Down's syndrome, colorectal cancer, familial hypercholesterolaemia, prostate cancer and thrombophilia. Genetic tests were mostly used for screening purposes and cost-effectiveness analysis is the most common type of economic study. There appear to be few studies examining medical students' attitudes or concerns raised by other healthcare professionals. ${ }^{7}$ Physicians will continue to be required to incorporate new genetic findings into patient care, which will hopefully improve because therapy will be tailor-made for both the disease and the patient. Improved patient care should be a primary goal for any national healthcare system, and the challenge now is to ensure that budgets are allocated for this type of testing. We wonder what Sir William would have done under the circumstances. Would he have been satisfied with a $99 \%$ positive result or would he have continued to investigate? Although eclectic, Osler was a stickler for clinical exactness.We doubt he would have been intimidated by gaining approval for the cost of establishing a DNA sequence. We believe he would have put the patient and the aim of a detailed diagnosis, as well as the potential learning experience for physicians, first. 


\section{CONCLUSIONS}

We believe that cost constraints inhibit 'Oslerian' teaching to the detriment of patient care. For our patient, the clinical diagnosis of her genetic disease was delayed for seven decades. However, the diagnosis was apparent and could have been made with a stethoscope and a flashlight. We performed a gene test that elucidated a signal transduction pathway that is highly relevant for the understanding of angiogenesis by medical students. However, the healthcare system will not defray the costs for these diagnoses, which interferes with our teaching obligations. We are curious how William Osler would have reacted to this issue and regret that we cannot ask him.

\section{Postscript}

Since preparing this report (20I I), the topic has become largely irrelevant due to the dramatic reduction in sequencing costs. Currently, the total human genome can be sequenced for US\$5,000 (we paid almost that much) and the costs are predicted to approach US $\$ 1,000$ in the near future. ${ }^{8}$ We could have had the other 20,000 genes and everything in between for approximately the same price. The more complex area now is what genomic medicine will do for our patients, but that remains to be seen.

\section{REFERENCES}

I Easter JS, Josephson A, Vinton DT et al. Clinical problem-solving. All in the family. N Engl J Med 2010; 362;21 14-20. http://dx.doi. org/I0.1056/NEJMcps090I4I6

2 Osler W. On a family form of recurring epistaxis, associated with multiple telangiectases of the skin and mucous membranes. Johns Hopkins Hospital Bulletin 1901; 12:333-7.

3 Shovlin CL. Hereditary hemorrhagic telangiectasia: pathophysiology, diagnosis and treatment. Blood Rev 2010; 24:203-19. http://dx.doi. org/I0.1016/j.blre.2010.07.00I

4 OslerW. Books and men. Dedication of the Boston Medical Library, January 12, 1901.

5 Becker F, van El CG, lbarreta D et al. Genetic testing and common disorders in a public health framework: how to assess relevance and possibilities. Background document to the ESHG recommendations on genetic testing and common disorders. Eur J Hum Genet 201 I; 19 Suppl I:S6-44. http://dx.doi.org/I0.1038/ejhg.2010.249

6 Antoñanzas F, Rodríguez-lbeas R, Hutter MF et al. Genetic testing in the European Union: does economic evaluation matter? Eur J Health Econ 20I I; Epub 20I I May 20.

7 Lose EJ. The emerging role of primary care in genetics. Curr Opin Pediatr 2008; 20:634-8.

8 Phimister EG, Feero WG, Guttmacher AE. Realizing genomic medicine. N Engl J Med 20 I 2; 366; 757-9. http://dx.doi.org/ I 0. I056/ NEJMeI 200749

\section{CONFERENCING AND EVENTS}

The Royal College of Physicians of Edinburgh has a unique blend of rooms providing the perfect location for your conference, meeting or event. The Victorian Great Hall, galleried New Library and the Georgian Cullen Suite are wonderful settings for dinners and receptions. The modern Conference Centre seats up to 300 people in raked seating and is complemented by breakout rooms seating from 10 to 150 people, a keypad voting system and video conferencing. The College provides a stunning setting for weddings and receptions and is licensed for both civil and religious ceremonies. Discounts are available for Fellows and Members, medical conferences and charities.

For more information or for a quotation, please contact the Events Team on +44 (0) I 3 I 225 7324; email events@rcpe.ac.uk or visit http://www.rcpe-venue.co.uk

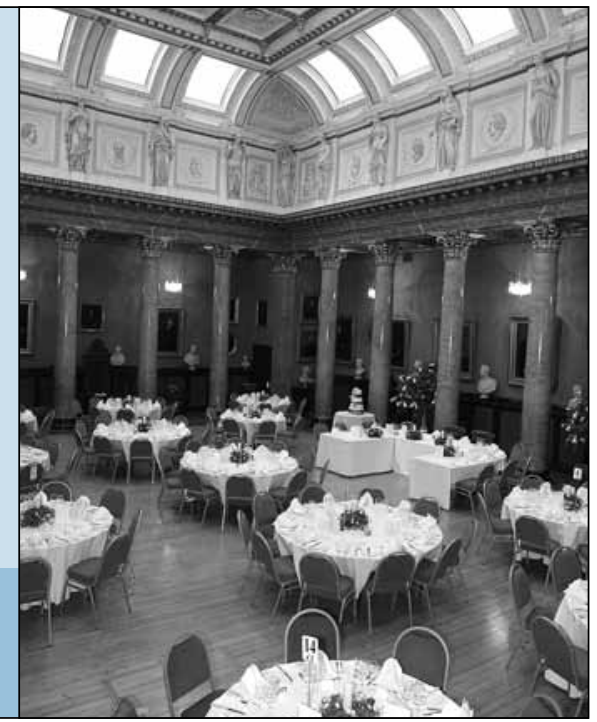

